\title{
Safety of rituximab in rheumatoid arthritis
}

\section{Profilo di sicurezza del rituximab nel trattamento dell'artrite reumatoide}

\author{
M. Covelli' ${ }^{1}$ P. Sarzi-Puttini ${ }^{2}$, F. Atzeni' ${ }^{2}$, P. Macchioni ${ }^{2}$ \\ ${ }^{1}$ DIMIMP-Sezione di Reumatologia, Università degli Studi di Bari, Italy; \\ ${ }^{2}$ Unità Operativa di Reumatologia, Arcispedale S. Maria Nuova, Reggio Emilia, Italy
}

\begin{abstract}
RIASSUNTO
La artrite reumatoide è una malattia cronica che predispone alla comparsa di complicanze rappresentate da malattie infettive, neoplasie e malattie cardiovascolari. Il rischio è aumentato dalla necessità di assumere a lungo farmaci immunomodulatori, quali ad esempio i farmaci biotecnologici.

La sicurezza del rituximab è stata valutata in un periodo di tempo medio (non superiore ai 10 anni) e i dati disponibili sono rassicuranti. Nei trials clinici condotti sia in pazienti già trattati (con antagonisti del TNF elo con methotrexate) sia in pazienti naive è emerso che il rituximab è tollerato anche dopo diversi cicli di terapia. La percentuale totale di eventi avversi è infatti rimasta stabile nei vari cicli. L'evento avverso più frequente era rappresentato dalla comparsa di reazioni infusionali. La percentuale di infezioni serie non aumentava dopo diversi cicli.

I dati ottenuti da esperienze condotte nella vita quotidiana confermano il buon profilo di tollerabilità.
\end{abstract}

Reumatismo, 2010; 62(2):101-106

\section{INTRODUCTION}

$\mathrm{P}$ atients with rheumatoid arthritis (RA) are at increased risk of manifestations such as serious infectious events (SIEs), malignancies and cardiovascular disease (1). Moreover, a long administration of drugs is required in this chronic disease, a condition that is responsible of a greater risk of side effects.

As an example, there is an almost 2-fold greater risk on a SIE in patients with RA than in general population (2). Furthermore bacterial infection, one of the leading cause of morbidity and mortality in RA patients (3), is not an uncommon side effect of therapy. In addition, the use of corticosteroids, even at low doses (10 mg per day or less), utilized in approximately $65 \%$ of patients in randomized clinical trials is an important contributory factor to the increased prevalence of SIEs among RA patients $(2,4)$.

Indirizzo per la corrispondenza:

Dott. Michele Covelli

Azienda Ospedaliera Universitaria Policlinico

P.zza Giulio Cesare, 11 - 70124 Bari

DIMIMP-Sezione di Reumatologia

Università degli Studi di Bari, Italy

E-mail: michelecovelli@ virgilio.it
The use of medications that further suppress the immune system, such as biologic agents, further increases the risk of developing an adverse event (AE). For these reasons, it is important to know the long-term safety of biologic drugs, with particular regard to the rate of infections, in order to ensure that treatments are both effective and safe over an extended period of time.

The aim of this report is to evaluate data assessing the safety (based on serious AEs, SIEs and malignancy) of rituximab (RTX) use in patients with RA, both in the short-term, after a single course, and in the medium-term (e.g. <10 years), after multiple courses.

Data on safety from clinical trials after a single course in patients with $R A$ already treated (with TNF-antagonists (a-TNF) and/or methotrexate (MTX)) and not previously treated

Data obtained from three (a phase IIa (5), a phase IIb (6), a phase III (7)) clinical trials in RA patients who have an inadequate response to $\geq 1$ a-TNF and/or MTX show that RTX is well tolerated.

In the 6-month REFLEX study (7) patients with active RA and an inadequate response to 1 or more a-TNF agents were randomized to receive intravenous RTX ( 1 course, consisting of 2 infusions of 
1,000 mg each) or placebo, both with background MTX. The overall incidence of AEs (Table I) occurring in patients receiving RTX (85\%) was similar to that observed in patients receiving placebo $(88 \%)$. Infusion-related reactions (IRR) (defined as any AE reported during or within 24 hours of infusion) were higher with rituximab versus placebo (29\% versus $23 \%$, respectively) during or following the first infusion. The majority of these IRR (e. g. nasopharyngitis, pyrexia, hypertension and dizziness) were of mild-to-moderate intensity and reduced with further infusions. The signs and symptoms of acute infusion reactions (e. g. pruritus, urticaria/rash, angioedema, fever, chills, rigors, sneezing, throat irritation/tightness, cough, bronchospasm, with or without hypotension or hypertension) were experienced by a greater proportion of rituximab-treated patients $(23 \%)$ than placebotreated patients (18\%) during the first infusion. However, the likelihood of patients experiencing an IRR diminished with the second infusion, where acute infusion reactions occurred in fewer patients receiving RTX $(8 \%)$ than placebo $(11 \%)$. Two RTX-treated patients experienced acute infusion reactions that were considered serious adverse events (SAEs) (anaphylaxis and hypertension, respectively), but most infusion reactions were mild or moderate in severity (National Cancer Institute Common Toxicity Criteria (NCI CTC) grade 1 or 2). Premedication with intravenous methylprednisolone (100 mg 30 minutes before each infusion) significantly reduced both the incidence and severity of acute infusion reactions.
For patients who experienced an infusion reaction, the recommended treatment included acetaminophen/paracetamol plus intramuscular or slow intravenous administration of antihistamine (diphenhydramine $\mathrm{HCl}$ ) and/or a bronchodilator, if indicated. In patients who experienced a severe infusion-related reaction, the infusion was immediately interrupted and symptomatic treatment was initiated. After all symptoms disappeared, the infusion was restarted at half the rate that had precipitated the reaction.

Two patients in the placebo group withdrew from the study because of AEs ( 1 because of gastric cancer and 1 because of thrombocytosis). Eight patients in the RTX group withdrew because of AEs, 5 because of IRR during the first infusion (anaphylactic reaction, urticaria, laryngeal edema, and cough and hoarseness) and 3 because of other events (cardiac tamponade, spontaneous abortion, and progressive RA). SAEs occurred at a higher incidence in placebo-treated patients $(10 \%)$ than in rituximab-treated patients (7\%) (Table I). There were no events that raised significant safety concerns. As for infectious episodes, treatment with RTX may increase the risk of infective complications because of a rapid depletion of normal B cells which can last for 2 to 6 months. However, serum immunoglobulin levels seem to remain stable after a conventional cycle of treatment and it is not consistently associated with an increased risk of bacterial infections.

The observed incidence of infections over 24 weeks in the REFLEX study was slightly higher in

Table 1 - Summary of adverse events.

\begin{tabular}{|c|c|c|c|c|c|c|c|}
\hline & \multicolumn{2}{|c|}{ Single course* } & \multicolumn{5}{|c|}{ Multiple courses** } \\
\hline & $\begin{array}{l}\text { Placebo/MTX } \\
n=209\end{array}$ & $\begin{array}{l}R T X / M T X \\
n=308\end{array}$ & $\begin{array}{l}\text { Course } 1 \\
n=2578\end{array}$ & $\begin{array}{l}\text { Course } 2 \\
n=1890\end{array}$ & $\begin{array}{l}\text { Course } 3 \\
n=1043\end{array}$ & $\begin{array}{l}\text { Course } 4 \\
n=425\end{array}$ & $\begin{array}{l}\text { Course } 5 \\
n=133\end{array}$ \\
\hline Any AE n (\%) & $183(88)$ & $261(85)$ & $2145(83)$ & $1391(74)$ & $675(65)$ & $248(58)$ & $81(61)$ \\
\hline Serious AEs n (\%) & $21(10)$ & $23(7)$ & $320(12)$ & $197(10)$ & $79(8)$ & $21(5)$ & $11(8)$ \\
\hline Infections/100 pt-yrs & 154.6 & 138.2 & 98.36 & 95.20 & 101.12 & 99.36 & 88.73 \\
\hline Serious infections/100 pt-yrs & 3.7 & 5.2 & 4.48 & 3.81 & 4.84 & 3.79 & 6.83 \\
\hline \multicolumn{8}{|c|}{$\begin{array}{l}\text { *Cohen SB, Emery P, Greenwald MW, Dougados M, Furie RA, Genovese MC, Keystone EC, Loveless JE, Burmester GR, Cravets MW, Hessey EW, Shaw T, } \\
\text { Totoritis MC. Arthritis Rheum 2006; 54: 2793-2806. **van Vollenhoven RF, Emery P, Bingham III CO, Keystone EC, Fleischmann R, Furst DE, Macey K, } \\
\text { Sweetser M, Kelman A, Rao R. J Rheumatol 2010; 37: 558-567. } \\
\text { A serious AEs was defined as any experience that was fatal, immediately life-threatening, required hospitalization or prolongation of an existing hospitali- } \\
\text { zation (with the exception of hospitalization for exacerbations of articular or periarticular manifestations of RA), resulted in persistent or significant disabi- } \\
\text { lity/incapacity, was a congenital anomaly/birth defect, was medically significant, or required intervention to prevent } 1 \text { or more of the outcomes listed abo- } \\
\text { ve. Serious infection events were pre-defined as infections that required intravenous antibiotics or met the regulatory criteria for a serious adverse event, } \\
\text { where at least one of the following applied: required inpatient hospitalization or prolongation of an existing hospitalization, were immediately life-threa- } \\
\text { tening, resulted in persistent or significant disability or incapacity, were medically significant, where an intervention was required to prevent one of the } \\
\text { previously mentioned outcomes, or were fatal. }\end{array}$} \\
\hline
\end{tabular}


RTX-treated patients (41\%) than in placebo-treated patients (38\%). Conversely, however, when the duration of response was taken into consideration, the overall infection rate per 100 patient-years was slightly higher in placebo-treated patients (154.6 per 100 patient-years) than in rituximab-treated patients (138.2 per 100 patient-years). Rates of serious infections were 3.7 per 100 patient-years (three serious infections) for placebo versus a marginally higher 5.2 per 100 patient-years for rituximab (seven serious infections). Importantly, there were no reports of tuberculosis or opportunistic infections over the 24 weeks of this study.

The tolerability data from the Phase IIa (5) and phase IIb DANCER (6) are consistent with those reported in the REFLEX study (7).

It is important to remember that in patients with lymphoma there have been reports of reactivation of hepatitis B and exacerbation of hepatitis C $(8,9,10)$. Sera et al. (10) reported an HBV surface antigen (HBsAg)-negative, anti-HBV surface antibody (anti-HBsAb)-positive patient converting to HBsAg-positive status with acute hepatitis during rituximab therapy, and they suggested prophylaxis with lamivudine in both HBsAg-positive and HBsAg negative (with evidence of previous infection, i.e., anti-HBV core antibody) prior to initiation of rituximab therapy, despite the presence of anti-HBsAb. Thus, RTX-based therapy may cause serious HBV-related complications and even death in both HBsAg-positive and HBsAg-negative patients (11). Therefore, baseline screening for HBV before initiation of RTX is mandatory.

In patients with early active RA not previously treated with MTX (MTX-naïve) (12), safety data at 24 weeks were consistent with those previously reported. The rate of serious infections in patients treated with infusions of $2 \times 500 \mathrm{mg}$ or $2 \times 1,000$ $\mathrm{mg}$ given every two weeks was $6.09,4.61$ and 3.73 events/100 pt-years in the placebo + MTX, RTX (2 x $500 \mathrm{mg}$ ) and RTX (2 x 1000) groups, respectively.

\section{Data on safety from clinical trials after multiple courses in patients with active $R A$ already treated (with a-TNF and/or MTX)}

Patients with active RA a-TNF and/or MTX-resistant who received $\geq 2$ courses of RTX during participation in one of 9 trials in an international clinical trial program were included in an analysis that involved a larger number of RTX-treated patients than previously reported, followed for multiple courses (13). Data were obtained from patients who had been treated in the following studies: phase IIa (5), phase IIb (6), phase III (7), REFLEX extension $(14,15)$, DANCER extension, SERENE (16), MIRROR (17), SUNRISE (18), SIERRA (19). A single course of treatment consisted of infusions of $2 \times 500 \mathrm{mg}$ or $2 \times 1,000 \mathrm{mg}$, given two weeks apart. All patients were offered retreatment with RTX based on clinical need.

Patients receiving placebo during placebo-controlled study periods were pooled to provide a placebo population. In the overall cohort there were patients who had undergone up to 10 courses of RTX. This analysis, however, only included patients with up to five courses, because the numbers of patients having more than five were small and the confidence intervals of point estimates were wide.

At data cut-off (November, 2007), a total of 2,578 patients were included, with 5,013.5 patient-years (pt-yrs) of observation, that received multiple courses of treatment $(1,890$ patients received $\geq 2$ courses; 1,043 patients received $\geq 3$ courses; 425 patients received $\geq 4$ courses, and 133 patients received $\geq 5$ courses) over a 6-year follow-up (Table I). Most study participants were woman, mean age was 53 years, and disease duration averaged 10 years. They have received a mean of three previous biologic or disease-modifying drugs (other than MTX), and more than half had previously been treated with a tumor necrosis factor inhibitor.

The rates for adverse events, serious adverse events, and overall infection rates remained stable following each course.

The overall rate of AEs was highest for the first course $(83 \%)$, declining with the second course $(74 \%)$, and remaining stable thereafter $(65 \%, 58 \%$ and $61 \%$ respectively for the third, fourth and fifth course) (Table I).

The most frequent AE was IRR (35\% of patients; $<1 \%$ considered serious). These reactions were observed in $25 \%$ of patients during the first course, typically manifesting as mild-to-moderate headache, pruritus, hypertension, and rash. Some $9 \%$ of patients required slowing or stopping the infusion because of these reactions during the first course. By the fifth course, all patients were tolerating the infusion, a pattern supporting the hypothesis that cytokine release syndrome is less likely with additional courses because of a lower B-cell load.

A total of 123 patients (5\%) withdrew from the study because of AEs. The rate of serious AEs remained stable following each course of treatment 
for up to five years (Table I). The most frequently serious AEs reported were: pneumonia (1\%), falls $(1 \%)$, myocardial infarction $(0,9 \%)$. The rate of myocardial infarction was an expected 0.56 per 100 patient-years, generally occurring in patients with risk factors. This was consistent with rates reported for other rheumatoid arthritis populations. Overall serum immunoglobulin levels decreased during follow-up, with $5 \%$ of patients having levels of $\operatorname{IgG}$ below the lower limit of normal on at least one occasion.

Classical observations have shown that $\mathrm{IgG}$ is the most important among serum immunoglobulins for protective immunity and that patients with low levels of $\mathrm{IgG}$ are at increased risk of serious infections. In this patient cohort, the rates of serious infections did not significantly increase when low IgG levels were detected. Older age and the concomitant use of steroids can contribute to decreases in IgG, and because corticosteroids were permitted in the clinical trials, it is unclear to what degree rituximab caused the fall in immunoglobulins. Irrespective of the underlying mechanisms for patients who had low levels of IgG, this subset of patients may be at higher risk for infections and should be monitored closely.

A total of $65 \%$ of patients experienced some type of infection (most commonly nasopharyngitis and upper respiratory tract infection) with a rate of 97.7 per 100 patient-years. Serious infections (such as pneumonia, cellulitis, and urinary tract infections) rates averaged 4.23 per 100 patient years for treatment courses one through four, but increased to 6.83 per 100 patient years with 5 courses of treatment (Table I).

There were no cases of serious opportunistic infections during the analysis period.

The overall incidence of malignancies other than non-melanoma skin cancer was 0.84 per 100 patient-years, and the adjusted standardized incidence ratio (SIR) compared with the general U. S. population was 1.05 (95\% CI 0.76 to 1.42). Thirty deaths occurred, and the adjusted standardized mortality rate compared with the overall U.S. population was 0.83 (95\% CI 0.56 to 1.18). Therefore, the results from this international six year followup program showed that RTX treatment was well tolerated for repeat and/or long term treatments with multiple courses in patients with advanced rheumatoid arthritis, with no increase in serious adverse events or serious infections. Authors pointed out that the study had limitations, such as pooling of information from trials in which number of treatment courses, disease status, and doses of RTX differed. The data were also constrained by the inclusion and exclusion criteria of the clinical trials. An extension of these data were presented at the October 2009 American College of Rheumatology meeting (20). As of September 2008, 3.095 patients had been treated with RTX providing 7.198 pt-years (pt-yrs) of exposure. Over 750 patients had been followed for $>3$ years with $2.365,1.581$, 1.038 and 497 pts receiving $\geq 2, \geq 3, \geq 4$ and $\geq 5$ courses, respectively.

Other than IRR, the safety profile of RTX was similar to the pooled placebo population. In the RTX group, the most frequent $\mathrm{AE}$ was IRR (35\%), most of which were NCI CTC grade 1 or 2 and occurred after the first infusion of the first course (23\%), with $<1 \%$ considered serious. The rate of serious infection was 4.25 events/100 pt-yrs and was comparable to that observed in the placebo population ( 4.33 events/100 pt-yrs). The most frequent serious infections were of the lower respiratory tract, predominantly pneumonia $(1 \%)$. No cases of TB or reactivation of hepatitis B were reported. Serious opportunistic infections were uncommon, but included one confirmed case of Pneumocystis jiroveci pneumonia in each of the RTX and pooled placebo groups and one case of progressive multifocal leukoencephalopathy (PML) in the RTX group. In this patient PML occurred in 2008, 18 months after receiving the last dose of RTX. Patient received also corticosteroids and MTX.

The casual relationship of PML to RTX in this case was unclear due to recognized risk factors including carcinoma of the oropharynx treated by chemoradiotherapy. Rates of myocardial infarction (MI) and stroke were consistent with the general RA population. The SIR for malignancy compared with the Surveillance, Epidemiology and End Results (SEER) 2008 database was 1.06 (95\% CI 0.81-1.37). The most frequently reported malignancy (excluding non-melanoma skin cancer) was breast cancer (SIR 0.69; 95\% CI 0.35-1.24). Authors concluded that in prolonged follow-up of RA pts treated with RTX in clinical trials, RTX has remained well tolerated over multiple courses with a stable safety profile similar to the pooled placebo population.

On October 2009, PML has been reported in a third patient with RA, occurring within 6 months after RTX treatment. Unlike both prior cases in patients with RA, the third patient had not previously treated with a-TNF and therefore is the first case of PML in a patient with RA treated with RTX. The 
risk of PML associated with rituximab remains uncertain because definite cases outside clinical trials are rare (21).

\section{Data on safety from "real-life" after multiple courses in patients with active RA already treated (with a-TNF and/or MTX)}

Patients enrolled in clinical trials may differ from patients who do not meet inclusion/exclusion criteria. Experiences with RTX (two infusions 1000 mg each, a fortnight apart) in "real-life" setting were conducted in patients with RA resistant to more than two a-TNF drugs. Re-treatment with a second cycle of RTX was offered if they had responded to the earlier one but flared. RTX was safe with no major side effects. Re-treatment with RTX was safe too (22). RTX is well tolerated in everyday clinical practice also in patients where a-TNF therapy is either unavailable or relatively contraindicated (23).

In conclusion, RTX is globally well-tolerated either in the short-term (e. g. after a single course), either in the medium-term (e. g. after multiple courses in a period $<10 \mathrm{yrs}$ ), either in a-TNF and/or MTX resistant either in MTX-naïve RA patients. Six-year follow-up data prove that RTX continues to be well-tolerated over several courses of treatment with a low rate of adverse events and infections similarly to other biologic agents used to treat RA (13) (12). Therefore, in a long-term condition like RA, treatment with RTX is safe over an extended period of time.

\section{SUMMARY \\ Rheumatoid arthritis (RA) is a chronic disease that requires a long-term administration of immunomodulatory drugs with a greater risk of side effects like malignancies, serious infections and cardiovascular diseases. Furthermore, pa- tients with RA are more prone than general population to these manifestations. \\ Safety of rituximab has been evaluated in the short-term ( 6 months) and in the medium-term (up to 10 years) in pa- tients who had been previously treated with antagonists of tumor necrosis factor (a-TNF) and/or with methotrexate (MTX) and in patients who were not. \\ Data obtained from clinical trials demonstrated that rituximab is well tolerated either after a single course or after mul- tiple courses. The overall rate of adverse events (AEs) was stable after the first three courses. The most frequent ad- verse event was infusion-related reactions (IRR). Serious infections did not increase after multiple courses. \\ Data from "real life" confirm that treatment with rituximab is well tolerated.}

Parole chiave - Rituximab, artrite reumatoide, sicurezza, infezioni, neoplasie.

Key words - Rituximab, rheumatoid arthritis, safety, infections, malignancies.

\section{REFERENCES}

1. Baecklund E, Iliadou A, Askling J, Ekbom A, Backlin C, Granath F, Catrina AI, Rosenquist R, Feltelius N, Sundstrom C, Klareskog L. Association of chronic inflammation, not its treatment, with increased lymphoma risk in rheumatoid arthritis. Arthritis Rheum 2006; 54: 692-701.

2. Doran MF, Crowson CS, Pond GR, O'Fallon WM, Gabriel SE. Frequency of infection in patients with rheumatoid arthritis compared with controls: a population-based study. Arthritis Rheum 2002; 46: 2287-93.

3. Symmons DP, Jones MA, Scott DL, Prior P. Longterm mortality outcome in patients with rheumatoid arthritis: early presenters continue to do well. J Rheumatol 1998; 25: 1072-7.

4. Bernatsky S, Hudson M, Suissa S. Anti-rheumatic drug use and risk of serious infections in rheumatoid arthritis. Rheumatology (Oxford) 2007; 46: 1157-60.

5. Edwards JC, Szczepanski L, Szechinski J, FilipowiczSosnowska A, Emery P, Close DR, Stevens RM, Shaw
T. Efficacy of B-cell-targeted therapy with rituximab in patients with rheumatoid arthritis. N Engl J Med 2004; 350: 2572-81.

6. Emery P, Fleischmann R, Filipowicz-Sosnowska A, Schechtman J, Szczepanski L, Kavanaugh A, Racewicz AJ, van Vollenhoven RF, Li NF, Agarwal S, Hessey EW, Shaw TM. The efficacy and safety of rituximab in patients with active rheumatoid arthritis despite methotrexate treatment: results of a phase IIB randomized, double-blind, placebo-controlled, dose-ranging trial. Arthritis Rheum 2006; 54: 1390-400.

7. Cohen SB, Emery P, Greenwald MW, Dougados M, Furie RA, Genovese MC, Keystone EC, Loveless JE, Burmester GR, Cravets MW, Hessey EW, Shaw T, Totoritis MC. Rituximab for rheumatoid arthritis refractory to anti-tumor necrosis factor therapy: Results of a multicenter, randomized, double-blind, placebo-controlled, phase III trial evaluating primary efficacy and safety at twenty-four weeks. Arthritis Rheum 2006; 54: 2793-806.

8. Dizdar O, Tapan U, Aksoy S, Harputluoglu H, Kilickap S, Barista I. Liver dysfunction after chemotherapy 
in lymphoma patients infected with hepatitis C. Eur J Haematol 2008; 80: 381-5.

9. Ennishi D, Yokoyama M, Terui Y, Takeuchi K, Ikeda $\mathrm{K}$, Tanimoto M, Hatake K. Does rituximab really induce hepatitis C virus reactivation? J Clin Oncol 2008; 26: 4695-6.

10. Sera T, Hiasa Y, Michitaka K, Konishi I, Matsuura K, Tokumoto Y, Matsuura B, Kajiwara T, Masumoto T, Horiike N, Onji M. Anti-HBs-positive liver failure due to hepatitis $\mathrm{B}$ virus reactivation induced by rituximab. Intern Med 2006; 45: 721-4.

11. Pei SN, Chen CH, Lee CM, Wang MC, Ma MC, Hu $\mathrm{TH}, \mathrm{Kuo} \mathrm{CY}$. Reactivation of hepatitis B virus following rituximab-based regimens: a serious complication in both HBsAg-positive and HBsAg-negative patients. Ann Hematol 2010; 89: 255-62.

12. Tak PP, Rigby WFC, Rubberth-Roth A, et al. Rituximab in combination with methotrexate (MTX) significantly inhibits joint damage and improves clinical outcomes in patients with early active RA who are naïve to MTX: a randomized active comparator placebo-controlled trial (IMAGE). Presented at: The American College of Rheumatology Annual Scientific Meeting; October 16-21, 2009; Philadelphia, PA.

13. van Vollenhoven RF, Emery P, Bingham CO, III, Keystone EC, Fleischmann R, Furst DE, Macey K, Sweetser M, Kelman A, Rao R. Longterm safety of patients receiving rituximab in rheumatoid arthritis clinical trials. J Rheumatol 2010; 37: 558-67.

14. Keystone EC, Fleischmann RM, Emery P, et al. Multiple courses of rituximab produce sustained efficacy in patients with rheumatoid arthritis with an inadequate response to one or more TNF inhibitor(s). Presented at: The American College of Rheumatology Annual Scientific Meeting; October 16-21, 2009; Philadelphia, PA.

15. Keystone EC, Fleischmann R, Emery P, Chubik A, Dougados MR, Baldassarre AR, et al. Efficacy and safety of repeat treatment courses of rituximab (RTX) in RA patients with inadequate response to tumor necrosis factor inhibitors; long-term experience from the REFLEX study [abstract]. Arthritis Rheum 2008 (Suppl 58): S303.
16. Emery P, Rigby WF, Combe B, Latinis K, Szczepanski LJ, Roschmann RA, et al. Efficacy and safety of rituximab (RTX) as first line biologic therapy in patients with active rheumatoid arthritis. Results of a phase III randomized, controlled study (SERENE) [abstract]. Arthritis Rheum 2008 (Suppl 58): S302.

17. Rubberth-Roth A, Tak PP, Bombardieri S, Zerbini C, Tremblay J, Carreno L, et al. Efficacy and safety of various dosing regimens of rituximab in patients with active RA: results of a phase III randomized study (MIRROR) [abstract]. Arthritis Rheum 2008 (Suppl 58): S301. Arthritis Rheum 2008; Suppl 58: S301.

18. Mease PJ, Cohen S, Gaylis NB, Chubik A, Kael AT, Greenwald M, et al. Efficacy, safety, and dose frequency of retreatment with rituximab in RA: results from a randomized controlled trial (SUNRISE) [abstract]. Arthritis Rheum 2008 (Suppl 58): S619.

19. Bingham C, Looney R, Deodhar A, Halsey N, Greenwald M, Lodding et al. Results from a controlled clinical trial (SIERRA) to evaluate primary and recall responses to immunizations in RA patients treated with rituximab [abstract]. Arthritis Rheum 2008 (Suppl 58): S900.

20. van Vollenhoven RF, Emery P, Bingham ICO, Keystone EC, Fleischmann R, Furst DE, et al. Long-term safety of rituximab: long-term follow-up of the RA clinical trials and retreatment. Presented at: The American College of Rheumatology Annual Scientific Meeting; October 16-21, 2009; Philadelphia, PA 2009.

21. Jois RN, Masding A, Somerville M, Gaffney K, Scott DG. Rituximab therapy in patients with resistant rheumatoid arthritis: real-life experience. Rheumatology (Oxford) 2007; 46: 980-2.

22. McGonagle D, Tan AL, Madden J, Taylor L, Emery P. Rituximab use in everyday clinical practice as a firstline biologic therapy for the treatment of DMARD-resistant rheumatoid arthritis. Rheumatology (Oxford) 2008; 47: 865-7.

23. Fleischmann RM. Progressive multifocal leukoencephalopathy following rituximab treatment in a patient with rheumatoid arthritis. Arthritis Rheum 2009; 60: 3225-8. 